\title{
Genome Mining Revealed Polyhydroxybutyrate Biosynthesis by Ramlibacter Agri Sp. Nov., Isolated from Agriculture Soil in Korea
}

\author{
Ram Hari Dahal \\ Kyonggi University \\ Jungmin Kim \\ Kyungpook National University \\ Dhiraj Kumar Chaudhary \\ Korea University Sejong Campus \\ Dong-Uk Kim \\ Sangji UniversitySemyung University \\ Hyein Jang \\ Semyung University \\ Jaisoo Kim ( $\nabla_{\text {jkimtamu@kgu.ac.kr) }}$ \\ Kyonggi University https://orcid.org/0000-0002-3876-3922
}

\section{Research Article}

Keywords: Ramlibacter agri, agriculture soil, polyhydroxybutyrate, biodegradable plastics, PHB biosynthesis

Posted Date: December 10th, 2021

DOI: https://doi.org/10.21203/rs.3.rs-1098143/v1

License: (c) (1) This work is licensed under a Creative Commons Attribution 4.0 International License. Read Full License

Version of Record: A version of this preprint was published at Antonie van Leeuwenhoek on March 19th, 2022. See the published version at https://doi.org/10.1007/s10482-022-01721-z. 


\section{Abstract}

A white-colony-forming, aerobic, motile and Gram-stain-negative bacterium, designated G-1-2-2 ${ }^{\top}$ was isolated from soil of agriculture field near Kyonggi University, Republic of Korea. Strain G-1-2-2 ${ }^{\top}$ synthesize the polyhydroxybutyrate and could grow at $10-35^{\circ} \mathrm{C}$. The phylogenetic analysis of its $16 \mathrm{~S}$ rRNA gene sequence, strain G-1-2-2 ${ }^{\top}$ formed a lineage within the family Comamonadaceae and clustered as a member of the genus Ramlibacter. The $16 \mathrm{~S}$ rRNA gene sequence of strain G-1-2-2 ${ }^{\top}$ showed high sequence similarities with Ramlibacter ginsenosidimutans BXN5-27 $7^{\top}$ (97.9\%), Ramlibacter monticola G-3-2 ${ }^{\top}$ (97.9\%) and Ramlibacter alkalitolerans $\mathrm{CJ} 661^{\top}$ (97.4\%). The sole respiratory quinone was ubiquinone-8 (Q-8). The major polar lipids were phosphatidylethanolamine, diphosphatidylglycerol, phosphatidylglycerol, and an unidentified phospholipid. The principal cellular fatty acids were $\mathrm{C}_{16: 0}$, cyclo- $\mathrm{C}_{17: 0}$, summed feature $3\left(\mathrm{C}_{16: 1} \omega 7 \mathrm{c}\right.$ and/or $\left.\mathrm{C}_{16: 1} \omega 6 c\right)$ and summed feature $8\left(\mathrm{C}_{18: 1} \omega 7 c\right.$ and/or $\left.\mathrm{C}_{18: 1} \omega 6 c\right)$. The genome of strain $\mathrm{G}-1-2-2^{\top}$ was $7,200,642$ bp long with 13 contigs, 6,647 protein-coding genes, and DNA G+C content of $68.9 \%$. The average nucleotide identity and in silico DNA-DNA hybridization values between strain G-1-2-2 ${ }^{\top}$ and closest members were $\leq 81.2$ and $24.1 \%$, respectively. The genome of strain $\mathrm{G}-1-2-2^{\top}$ showed eight putative biosynthetic gene clusters responsible for various secondary metabolites. Genome mining revealed the presence of ato $B$, atoB2, phaS, $p h b B$, phbC, $b h b D$ genes in the genome which are responsible for polyhydroxybutyrate biosynthesis. Based on these data, strain G-1-2-2 ${ }^{\top}$ represents a novel species in the genus Ramlibacter, for which the name Ramlibacter agri sp. nov. is proposed. The type strain is G-1-2-2 ${ }^{\top}$ (= KACC $21616^{\top}=$ NBRC $\left.114389^{\top}\right)$.

\section{Introduction}

The genus Ramlibacter was first proposed by Hulin et al. with the description of cyst-producing bacteria Ramlibacter tataouinensis and Ramlibacter henchirensis isolated from subdesert soil (Heulin et al. 2003). Later on, the genus description has been emended by Lee et al. regarding colony colour, extracellular polymeric substance production, motility and aesculin hydrolysis (Lee et al. 2014). To date, 11 species of the genus Ramlibacter with validly published names have been reported (https://lpsn.dsmz.de/genus/ramlibacter; accessed date: 2021.11.11) (Parte et al. 2020). Members of the genus Ramlibacter are characterized by aerobic, Gram-stain-negative, rod- to coccoid-shaped, motile or nonmotile and contain ubiquinone-8 $(\mathrm{Q}-8)$ as a predominant isoprenoid quinone; $\mathrm{C}_{16: 0}$, cyclo- $\mathrm{C}_{17: 0 \text {, and summed }}$ feature $3\left(\mathrm{C}_{16: 1} \omega 6 c\right.$ and/or $\left.\mathrm{C}_{16: 1} \omega 7 c\right)$ as principal fatty acids; phosphatidylethanolamine, diphosphatidylglycerol and phosphatidylglycerol as major polar lipids (Heulin et al. 2003; Lee et al. 2014; Chaudhary and Kim 2017). Most of the members of the genus Ramlibacter have been isolated from soil in addition to few members from aquatic niches (Props et al. 2019; Kim et al. 2021).

In this study, a novel member of the genus Ramlibacter isolated from soil of agriculture field near Kyonggi University and its taxonomic position was determined during the study of diversity of soil microorganisms. Moreover, whole-genome analysis of strain G-1-2-2 ${ }^{\top}$ has been explored providing insights into polyhydroxybutyrate biosynthesis. 


\section{Materials And Methods}

\section{Ecology, isolation and preservation}

Strain G-1-2-2 ${ }^{\top}$ was isolated from soil of agriculture field, geographically located near Kyonggi University, Suwon, Republic of Korea ( $37^{\circ} 17^{\prime} 56.9^{\prime \prime} \mathrm{N}$ and $\left.127^{\circ} 02^{\prime} 23.2^{\prime \prime} \mathrm{E}\right)$ and subjected to polyphasic approach for its taxonomic description. A modified culture method with six-well Transwell plates (Corning Inc., NY, USA) was utilized for isolation. Sieved $3 \mathrm{~g}$ soil was kept on the bottom of each Transwell plate and $3 \mathrm{ml}$ Reasoner's $2 \mathrm{~A}$ (R2A) broth (Kisan Bio, Seoul, Korea) was added to each insert. Then, $100 \mu \mathrm{l}$ soil suspension $(1 \mathrm{~g}$ soil in $9 \mathrm{ml}$ distilled water; thoroughly stirred and settled) was added to the insert. The Transwell plate was incubated in a shaker at 120 r.p.m. for 4 weeks at $28^{\circ} \mathrm{C}$. After 4 weeks, the culture was serially diluted, and $100 \mu \mathrm{l}$ of each dilution was spread on R2A agar plates. Isolation, maintenance and preservation of strain G-1-2-2 ${ }^{\top}$ was done as described in previous study (Dahal et al. 2018).

\section{Phylogenetic analysis}

Genomic DNA of strain G-1-2-2 ${ }^{\top}$ was isolated by using InstaGene Matrix kit (Life Science Research; Bio-Rad, CA, USA) following manufacturer's instruction. The 16S rRNA gene was amplified by using PCR (Bio-Rad, CA, USA) with forward and reverse primers $27 \mathrm{~F}$ and $1492 \mathrm{R}$, respectively (Frank et al. 2008). Applied Biosystems 3770XL DNA analyzer was used with a BigDye Terminator cycle sequencing Kit v.3.1 (Applied Biosystems, CA, USA) for gene sequencing. After sequencing, nearly complete sequence of 16S rRNA genes was assembled using SeqMan software (DNASTAR Inc., WI, USA). Phylogenetically closest neighbours were identified using the EzBioCloud server (Yoon et al. 2017b). All the 16S rRNA gene sequences of phylogenetically closest neighbours were retrieved from the EzBioCloud server (https://www.ezbiocloud.net/identify) and ncbi GenBank database (https://www.ncbi.nlm.nih.gov/nucleotide). All the retrieved sequences along with the sequence of strain G-12-2 ${ }^{\top}$ were aligned using in silico by sina alignment (https://www.arb-silva.de/aligner) (Pruesse et al. 2012). Neighbour-joining (NJ), maximum-likelihood (ML) and maximum-parsimony (MP) phylogenetic trees were reconstructed using mega v7.0.26 software (Kumar et al. 2016).

\section{Reference strains}

Based on the 16S rRNA gene sequence similarities and phylogenetic analyses Ramlibacter ginsenosidimutans KACC $17527^{\top} ; 3$, R. monticola KACC $19175^{\top} ; 4$, R. alkalitolerans KACC $19305^{\top}$ were used as references and analysed under identical conditions for API, biochemical and fatty acid analyses.

\section{Genome analyses}

For genome sequencing, extraction of genomic DNA was carried out by using DNeasy Blood and Tissue kits (Qiagen). Whole-genome shotgun sequencing of strain G-1-2-2 ${ }^{\top}$ was performed at Macrogen (Republic of Korea) using the Illumina HiSeq 2500 platform using a 150-bp $\times 2$ paired-end kit. The whole-genome sequences were assembled by SPAdes v3.2 (Bankevich et al. 2012). The authenticity of the assembled genome was analysed by comparing $16 \mathrm{~S}$ rRNA gene sequence of strain G-1-2-2 ${ }^{\top}$ using ncbi Basic Local Alignment Search Tool (blastn) (Zhang et al. 2000). Potential contamination of genome assembly was 
examined in silico by ContEst16S algorithm using EzBioCloud server (https://www.ezbiocloud.net/tools/contest16s) (Lee et al. 2017). Then, the whole-genome sequence (WGS) of strain G-1-2-2 ${ }^{\top}$ was annotated using the Rapid Annotation using Subsystem Technology (RAST; https://rast.nmpdr.org) server (Aziz et al. 2008) and Prokaryotic Genome Annotation Pipeline (PGAP; https://www.ncbi.nlm.nih.gov/genome/annotation_prok) (Tatusova et al. 2016). All the genome sequences of reference strains were retrieved from ncbi database. The DNA G+C content of strain G-1-2-2 ${ }^{\top}$ and other references used in this study were calculated based on respective whole-genome sequences. Genome-based relatedness between $\mathrm{G}-1-2-2^{\top}$ and phylogenetically closest neighbours were determined based on ANI (Average Nucleotide Identity) in silico by OrthoANlu (https://www.ezbiocloud.net/tools/ani) algorithm (Yoon et al. 2017a). The phylogenomic tree was reconstructed in silico using concatenated alignment of 92 core genes with UBCGs software (Na et al. 2018). Digital DNA-DNA hybridization (dDDH) was calculated in silico by the Genome-to-Genome Distance Calculator (GGDC 3.0) using the blast method (https://ggdc.dsmz.de/ggdc.php\#) (Meier-Kolthoff et al. 2021). Graphical circular map was constructed by using CGView (http://cgview.ca) server (Grant and Stothard 2008). Transfer RNAs (tRNAs) and ribosomal RNAs (rRNAs) were analysed using tRNAscan-SE (http://lowelab.ucsc.edu/tRNAscan-SE) (Schattner et al. 2005) and rnammer (http://www.cbs.dtu.dk/services/RNAmmer) (Lagesen et al. 2007) servers. The CRISPR genes and Cas clusters were determined in silico using the CRISPRCasFinder (https://crisprcas.i2bc.parissaclay.fr) server. The antiSMASH server (https://antismash.secondarymetabolites.org/\#!/start) was used to identify the biosynthetic gene clusters (BGCs) for various secondary metabolites (Blin et al. 2019).

\section{Morphological, biochemical and chemotaxonomic analyses}

The cell morphology of strain G-1-2-2 ${ }^{\top}$, grown on R2A agar plate for $4-5$ days at $28^{\circ} \mathrm{C}$ was observed by using TEM (transmission electron microscopy; Talos L120C; FEI). The colony morphology of strain of G-1-2-2 ${ }^{\top}$ was observed using a Zoom Stereo Microscope (SZ61; Olympus, Tokyo, Japan). Gram-staining was performed as described previously (Doetsch 1981). The cell motility was examined in R2A (Reasoner's Agar No. 2; MB cell; KisanBio, Seoul, Republic of Korea) soft agar medium consisting $0.4 \%$ agar A (Bio Basic; Ontario, Canada). Oxidase and catalase activities of strain $\mathrm{G}-1-2-2^{\top}$ was examined using $1 \%$ tetra-methyl-p-phenylenediamine dihydrochloride and $3 \%(\mathrm{v} / \mathrm{v}) \mathrm{H}_{2} \mathrm{O}_{2}$, respectively. Growth at various temperatures $\left(0-40^{\circ} \mathrm{C}\right)$ on $\mathrm{R} 2 \mathrm{~A}$ agar plates was observed for 10 days. Growth was monitored on various bacteriological media including brain heart infusion agar (BHI; Oxoid), Luria-Bertani agar (LBA; Oxoid), marine agar 2216 (Becton), nutrient agar (NA; Oxoid), R2A agar, sorbitol MacConkey agar (MA; Oxoid), tryptone soya agar (TSA; Oxoid), and veal infusion agar (VIA; Becton). DNase activity of strain G-1-2-2 ${ }^{\top}$ was analysed by using DNase agar (Oxoid). Salt tolerance was checked in R2A broth supplemented with $\mathrm{NaCl}$ [Duksan Chemicals, Republic of Korea; $0-$ $5 \%(\mathrm{w} / \mathrm{v})$ at $0.5 \%$ interval]. The $\mathrm{pH}$ range was observed at $28^{\circ} \mathrm{C}$ in $\mathrm{R} 2 \mathrm{~A}$ broth $(\mathrm{pH} 4-12$ in increments of 0.5 pH units). Hydrolysis of Tween 80, Tween 60 and Tween 40 were analysed as described by Smibert \& Krieg (Smibert and Krieg 1994). The anaerobic growth of strain G-1-2-2 ${ }^{\top}$ was monitored for 10 days on R2A agar plate at $28^{\circ} \mathrm{C}$ with BD GasPak ${ }^{\mathrm{TM}} \mathrm{EZ}$ Gas Generating Pouch System (BD). Hydrolysis of casein CM-cellulose, starch and tyrosine were assessed as described in previous study (Dahal and Kim 2018). Hydrogen sulfide $\left(\mathrm{H}_{2} \mathrm{~S}\right)$ and indole production were checked in SIM sulfide indole motility medium (SIM; Oxoid). Malachite green staining was done to analyse spore. Other physiological tests were examined by using API 20NE and 
API ID 32GN kits (bioMérieux). The enzyme activities of strain G-1-2-2 ${ }^{\top}$ and other references were examined by using an API ZYM kit (bioMérieux) following the manufacturer's instructions.

For the determination of fatty acids, cells of reference strains and strain G-1-2-2 ${ }^{\top}$ were harvested from identical culture condition (at $28^{\circ} \mathrm{C}$ on R2A agar plate for 4 days). Fatty acid methyl esters (FAME) of harvested cells were extracted using MIDI protocol technical note \#101 (http://midiinc.com/pdf/MIS_Technote_101.pdf). Extracted FAMEs were analysed using a HP 6890 Series GC System (Gas chromatograph; Hewlett Packard; Agilent Technologies) and the FAME compositions (percentage of totals) were identified with TSBA6 database of the Microbial Identification System (Sasser 1990). The polar

lipids and isoprenoid quinones were extracted from freeze-dried cells following the protocol of Minnikin et al. (Minnikin et al. 1984). Appropriate reagents for the spot detection were used as described by Komagata and Suzuki (Komagata and Suzuki 1988).

\section{Result And Discussions}

\section{Phylogenetic analysis}

The 16S rRNA gene sequence of strain G-1-2-2 ${ }^{\top}$ was 1,483 bp long and has been deposited at GenBank/EMBL/DDBJ database under the accession MN685325. Phylogenetic analysis based on 16S rRNA gene sequence showed that strain G-1-2-2 ${ }^{\top}$ formed a lineage within the family Comamonadaceae and clustered with members of the genus Ramlibacter. The 16S rRNA gene sequence of strain G-1-2-2 ${ }^{\top}$ showed high sequence similarities with Ramlibacter ginsenosidimutans BXN5-27 ${ }^{\top}$ (97.9\%), Ramlibacter monticola G$3-2^{\top}(97.9 \%)$, and Ramlibacter alkalitolerans $\mathrm{CJ} 661^{\top}(97.4 \%)$. The sequence similarities of strain $\mathrm{G}-1-2-2^{\top}$ with all other members of the genus Ramlibacter were $<96.7 \%$. Strain G-1-2-2 ${ }^{\top}$ was clustered with Ramlibacter alkalitolerans, Ramlibacter monticola, and Ramlibacter ginsenosidimutans in all three trees i.e. ML, NJ and MP (Figs. 1, S1 and S2). In addition, in all phylogenetic trees, strain G-1-2-2 ${ }^{\top}$ formed a distinct lineage. The phylogenetic positions in all three NJ, ML and MP trees strongly support to assign strain G-1-2$2^{\top}$ as a novel member within the genus Ramlibacter.

\section{Genomic analysis}

The ContEst16S analysis of strain G-1-2-2 ${ }^{\top}$ showed that the genome was not contaminated. Whole-genome shotgun sequence has been deposited at DDBJ/ENA/GenBank under the accession JABBFX000000000. The genome size and N50 value of strain G-1-2-2 ${ }^{\top}$ are 7,200,642 bp and 3,830,216 bp, respectively. The genome has 13 scaffolds and coverage of 139.0-fold (Table S1). The graphical genomic map revealed the presence of six rRNAs and 52 tRNAs (Fig. 2). The DNA G+C content of strain G-1-2-2 ${ }^{\top}$ is $68.9 \%$ which is within the range of Ramlibacter species (Heulin et al. 2003; Lee et al. 2014). The ANI threshold for species demarcation is recommended at 95-96\% (Richter and Rosselló-Móra 2009) and ANI values between strain G-1-2-2 ${ }^{\top}$ and other Ramlibacter members were $\leq 81.2 \%$ (Table 1). The dDDH values of $\leq 24.1 \%$ was much lower value than the species threshold of $70 \%$ recommended for species delineation (Meier-Kolthoff et al. 2013) (Table 1). These values clearly show that strain $G-1-2-2^{\top}$ represents a novel member within the genus Ramlibacter (Meier-Kolthoff et al. 2013). Furthermore, the phylogenomic position of strain G-1-2-2 ${ }^{\top}$ obtained from tree 
reconstructed using UBCGs (concatenated alignment of 92 core genes) also showed that strain G-1-2-2 ${ }^{\top}$ is a novel member of the genus Ramlibacter (Fig. S3).

Table 1

Average nucleotide identity (OrthoANlu) and digital DNA-DNA hybridization (dDDH) between strain $\mathrm{G}-1-2-2^{\top}$ and other members of the genus Ramlibacter.

\begin{tabular}{|c|c|c|c|}
\hline \multirow[t]{2}{*}{ Strains } & \multirow[t]{2}{*}{ GenBank accessions } & \multicolumn{2}{|c|}{$\mathrm{G}-1-2-2^{\top}$} \\
\hline & & ANI & $\mathrm{dDDH}$ \\
\hline Ramlibacter algicola $\mathrm{CrO}^{\top}$ & JAEDA0000000000 & 78.4 & 21.6 \\
\hline Ramlibacter alkalitolerans KACC $19305^{\top}$ & JAEQND000000000 & 81.0 & 24.1 \\
\hline Ramlibacter aquaticus LMG $30558^{\top}$ & JADDOJ000000000 & 78.8 & 22.0 \\
\hline Ramlibacter ginsenosidimutans KACC $17527^{\top}$ & JAEPWM000000000 & 80.8 & 24.0 \\
\hline Ramlibacter henchirensis DSM $14656^{\top}$ & SMLM00000000 & 78.7 & 21.6 \\
\hline Ramlibacter humi $18 \times 22-1^{\top}$ & SMLK00000000 & 79.1 & 22.0 \\
\hline Ramlibacter monticola KACC $19175^{\top}$ & JAEQNE000000000 & 81.2 & 24.1 \\
\hline Ramlibacter pinisoli $\mathrm{MAH}-25^{\top}$ & WSEL00000000 & 79.0 & 22.0 \\
\hline Ramlibacter rhizophilus CСТCC АВ2015357' & SMLL00000000 & 77.8 & 21.4 \\
\hline Ramlibacter solisilvae $5-10 \mathrm{~T}^{\top}$ & СР010951 & 79.1 & 22.0 \\
\hline Ramlibacter tataouinensis ТТВ310 ${ }^{\top}$ & СР000245 & 79.6 & 22.4 \\
\hline
\end{tabular}

The RAST analysis revealed the presence of 335 subsystems, 70 polyhydroxybutyrate (PHB) metabolism and five secondary metabolisms (alkaloid biosynthesis from L-lysine: one, auxin biosynthesis: four; Fig. S4). The genome of strain G-1-2-2 ${ }^{\top}$ consists eight putative BGCs (arylpolyene, RiPP-like, linaridin, T1PKS, NRPSlike, terpene, redox-cofactor, betalactone, and phosphonate) were revealed by antiSMASH analysis (Table 2). The genome contained the genes such as atoB, atoB2, phaS, phbB, phbC, bhbD which are responsible for PHB biosynthesis. In addition, the genome contained genes encoding a $\beta$-ketothiolase (WP_169422749), and class I poly(R)-hydroxyalkanoic acid synthase (WP_169420190, WP_169422744). These genes are the key enzyme for PHB biosynthesis (Catone et al. 2014). The PHB derived from bacteria not only be used as carbon and energy reserve materials (Muneer et al. 2020) but also could be utilized in making biodegradable plastics (Getachew and Woldesenbet 2016; Mostafa et al. 2020). 
Table 2

Numbers of predicted secondary metabolite biosynthetic gene clusters (smBGC) of G-1-2-2 ${ }^{\top}$ genome. The BGCs were determined using anti-SMASH (v5.1.2). T1PKS, type I polyketide synthase; NRPS, non-ribosomal peptide synthetase cluster; RiPP-like; other unspecified ribosomally synthesised and post-translationally modified peptide; NRP, non-ribosomal peptide; APE Ec, aryl polyene.

\begin{tabular}{|c|c|c|c|c|c|c|c|}
\hline Cluster & Contig & BGC type & From & To & $\begin{array}{l}\text { Most } \\
\text { similar } \\
\text { known } \\
\text { cluster }\end{array}$ & $\begin{array}{l}\text { Core } \\
\text { biosynthetic } \\
\text { gene }\end{array}$ & $\begin{array}{l}\text { Additional } \\
\text { biosynthetic } \\
\text { gene }\end{array}$ \\
\hline 1 & 1 & arylpolyene & 459,642 & 503,219 & $\begin{array}{l}\text { APE Ec, } \\
\text { othter } \\
(36 \%)\end{array}$ & 2 & 11 \\
\hline 2 & 1 & $\begin{array}{l}\text { RiPP-like, } \\
\text { linaridin }\end{array}$ & $1,132,400$ & $1,155,291$ & - & 2 & 0 \\
\hline 3 & 1 & RiPP-like & $1,577,922$ & $1,588,755$ & - & 1 & 0 \\
\hline 4 & 1 & $\begin{array}{l}\text { T1PKS, } \\
\text { NRPS-like }\end{array}$ & $2,474,608$ & $2,523,951$ & & 2 & 1 \\
\hline 5 & 1 & terpene & $3,171,214$ & $3,192,922$ & - & 2 & 2 \\
\hline 6 & 1 & $\begin{array}{l}\text { redox- } \\
\text { cofactor }\end{array}$ & $3,626,740$ & $3,648,809$ & $\begin{array}{l}\text { lankacidin } \\
\text { C, NRP + } \\
\text { polyketide } \\
(13 \%)\end{array}$ & 3 & 1 \\
\hline 7 & 3 & betalactone & 339,687 & 370,393 & $\begin{array}{l}\text { fengycin, } \\
\text { NRP } \\
(13 \%)\end{array}$ & 2 & 6 \\
\hline 8 & 3 & phosphonate & 470,992 & 511,870 & - & 1 & 6 \\
\hline
\end{tabular}

Physiological analysis

The cells of strain G-1-2-2 ${ }^{\top}$ are rod-shaped (Fig. S5), aerobic, catalase and oxidase positive, non-sporeforming, Gram-stain-negative and motile with flagella. Strain G-1-2-2 ${ }^{\top}$ formed while-colony on R2A agar plate and PHB was accumulated in its cells (Fig. S5). Weak growth was observed in anaerobic condition when incubated for 10 days. Strain G-1-2-2 ${ }^{\top}$ hydrolysed urea but not CM-cellulose, casein, starch, gelatin, tyrosine, DNA, Tween 80, Tween 60 and Tween 40. The differential physiological characteristics are given on Table 3 along with its closest reference strains.

Table 3. Phenotypic characteristics of strain $\mathrm{G}-1-2-2^{\top}$ of the genus Ramlibacter that differentiates with phylogenetically related type species.

Strains: 1, G-1-2-2' $; 2$, R. ginsenosidimutans KACC $17527^{\top} ; 3$, R. monticola KACC $19175^{\top} ; 4, R$. alkalitolerans KACC $19305^{\top}$. All data were obtained from this study. + , positive; w, weak; - , negative. 


\begin{tabular}{|c|c|c|c|c|}
\hline Characteristic & 1 & 2 & 3 & 4 \\
\hline Maximum growth temperature $\left({ }^{\circ} \mathrm{C}\right)$ & 35 & 37 & 37 & 37 \\
\hline Highest salt tolerance $(\%, w / v)$ & 1.0 & 0.5 & 0.5 & 0.5 \\
\hline $\mathrm{pH}$ range & $5.0-11.0$ & $6.0-9.0$ & $5.5-10.0$ & $5.0-10.5$ \\
\hline Nitrate reduction & - & + & - & + \\
\hline Esculin hydrolysis & w & - & w & - \\
\hline Urease & + & - & + & - \\
\hline \multicolumn{5}{|l|}{ Enzyme activity (API ZYM) } \\
\hline Acid phosphatase & + & - & + & - \\
\hline Alkaline phosphatase & + & - & + & - \\
\hline Cystine arylamidase & - & - & - & + \\
\hline Esterase (C4) & + & + & - & + \\
\hline Esterase lipase (C8) & + & - & + & + \\
\hline Leucine arylamidase & + & - & + & - \\
\hline Lipase (C14) & - & - & - & + \\
\hline Napthol-AS-BI-phosphohydrolase & + & - & + & + \\
\hline Valine arylamidase & + & - & + & + \\
\hline a-galactosidase & - & - & - & + \\
\hline$\beta$-galactosidase & - & + & - & - \\
\hline$\beta$-glucosidase & - & + & - & - \\
\hline \multicolumn{5}{|l|}{ Assimilation from } \\
\hline d-glucose & - & + & - & - \\
\hline I-arabinose & - & - & - & + \\
\hline d-mannose & - & - & - & + \\
\hline d-mannitol & - & - & - & + \\
\hline $\mathrm{N}$-acetyl-glucosamine & - & - & - & + \\
\hline d-maltose & - & + & - & - \\
\hline DNA G + C content $(\%)$ & 68.9 & 68.7 & 69.3 & 69.2 \\
\hline
\end{tabular}


The principal fatty acids of strain G-1-2-2 ${ }^{\top}$ were $C_{16: 0}$, cyclo- $C_{17: 0}$, summed feature $3\left(\mathrm{C}_{16: 1} \omega 7 \mathrm{c}\right.$ and/or $\left.\mathrm{C}_{16: 1} \omega 6 c\right)$ and summed feature $8\left(\mathrm{C}_{18: 1} \omega 7 c\right.$ and/or $\left.\mathrm{C}_{18: 1} \omega 6 c\right)$, similar with the genus Ramlibacter. However, the differences in major and minor fatty acids in addition to the presence of minor fatty acids such as iso$\mathrm{C}_{10: 0}$, iso- $\mathrm{C}_{19: 0 \text {, }}$, iso- $\mathrm{C}_{8: 0} 3-\mathrm{OH}$, and iso- $\mathrm{C}_{15: 0} 3-\mathrm{OH}$ differentiate strain $\mathrm{G}-1-2-2^{\top}$ from other closely related type species of the genus Ramlibacter (Table S2). The sole respiratory quinone was ubiquinone-8 (Q-8) and the major polar lipids of strain G-1-2-2 ${ }^{\top}$ were phosphatidylethanolamine (PE), diphosphatidylglycerol (DPG), phosphatidylglycerol (PG) and an unidentified phospholipid (PL). In addition, one unidentified aminolipid (AL) and three unidentified polar lipids (L1-L3) were also detected in TLC chromatograms (Fig. S6).

Based on above discussed data, strain G-1-2-2 ${ }^{\top}$ represents a novel species in the genus Ramlibacter for which the name Ramlibacter agrisp. nov. is proposed.

\section{Description of Ramlibacter agri sp. nov.}

Ramlibacter agri (a'gri. L. gen. n. agri of an agriculture field, referring to the source of isolation).

Cells (1.5-2.5 $\mu \mathrm{m}$ long and 0.6-0.9 $\mu \mathrm{m}$ wide) are rod-shaped, aerobic, Gram-stain-negative and motile with flagella. Colonies (1-2 mm) are white-coloured, circular and convex on R2A agar plate after 5 days at $28^{\circ} \mathrm{C}$. Colonies grow well on R2A agar, weakly on TSA and no growth is observed on NA, BHI, LBA, MA, VIA and marine agar 2216 . Colonies grow at $10-35^{\circ} \mathrm{C}$ (optimum, $25-30^{\circ} \mathrm{C}$ ) and pH 5.0-11.0 (optimum pH, 7.0-8.5). Cells grow optimally in the absence of $\mathrm{NaCl}$ but tolerate $1 \%(\mathrm{w} / \mathrm{v})$ of $\mathrm{NaCl}$. Catalase and oxidase are positive. Hydrogen sulfide is not produced. Nitrate is not reduced to nitrite. Glucose is not fermented. The type strain shows the following enzyme activities: positive for alkaline phosphatase, esterase (C4), esterase lipase (C8), leucine arylamidase, valine arylamidase, acid phosphatase and napthol-AS-BI-phosphohydrolase; and negative for lipase (C14), cystine arylamidase, trypsin, $\alpha$-chymotrypsin, $\alpha$-galactosidase, $\beta$-galactosidase, $\alpha$ glucosidase, $\beta$-glucosidase, $N$-acetyl- $\beta$-glucosaminidase, $\beta$-glucuronidase, $\alpha$-mannosidase and $\alpha$-fucosidase. I-rhamnose, lactic acid, 3-hydroxybenzoic acid, d-mannitol, I-arabinose, propionic acid, 3-hydroxybutyric acid, 4-hydroxybenzoic acid, and I-proline are assimilated. The sole respiratory quinone is Q-8. The principal cellular fatty acids are $\mathrm{C}_{16: 0}$, cyclo- $\mathrm{C}_{17: 0}$, summed feature $3\left(\mathrm{C}_{16: 1} \omega 7 \mathrm{c}\right.$ and/or $\left.\mathrm{C}_{16: 1} \omega 6 c\right)$ and summed feature $8\left(\mathrm{C}_{18: 1} \omega 7 c\right.$ and/or $\left.\mathrm{C}_{18: 1} \omega 6 c\right)$. The major polar lipids are phosphatidylethanolamine, diphosphatidylglycerol, phosphatidylglycerol, and an unidentified phospholipid. The DNA G + C content of the type strain is $68.9 \%$.

The type strain, G-1-2-2 ${ }^{\top}\left(=\right.$ KACC $21616^{\top}=$ NBRC $\left.114389^{\top}\right)$, was isolated from soil of agriculture field, geographically located near Kyonggi University, Suwon, Republic of Korea $\left(37^{\circ} 17^{\prime} 56.9^{\prime \prime} \mathrm{N}\right.$ and $\left.127^{\circ} 02^{\prime} 23.2^{\prime \prime E}\right)$. The GenBank/EMBL/DDBJ accession numbers for the 16S rRNA gene sequence and the whole genome sequence of strain G-1-2-2 ${ }^{\top}$ are MN685325 and JABBFX000000000, respectively.

\section{Declarations}

\section{Funding information}

This paper was supported by the Semyung University Research Grant of 2020. 
Acknowledgements

We thank Prof. Aharon Oren (The Hebrew University of Jerusalem, Israel) for his expert suggestions concerning the correct species epithet and etymology.

\section{Conflict of Interest}

The authors declare that there are no conflicts of interest regarding the publication of this manuscript.

\section{Ethical Statement}

This study does not describe any experimental work related to human.

\section{Author contributions}

R.H.D., J.K. $\left(2^{\text {nd }}\right)$, D.K.C. conceived, designed and conducted all the experiments. D.U.K. interpreted the data. J.K. $\left(6^{\text {th }}\right)$ and H.J. coordinated and supervised the study. R.H.D., J.K. (both), D.K.C. and D.U.K. analysed all the data and prepared the manuscript. All the authors read, discussed, edited and approved the final draft of the manuscript.

\section{Data availability}

The genome sequence and 16s rRNA gene sequence are publicly available in NCBI database.

\section{Informed consent}

Not applicable

\section{References}

1. Aziz RK, Bartels D, Best AA, et al (2008) The RAST Server: Rapid Annotations using Subsystems Technology. BMC Genomics 9:75

2. Bankevich A, Nurk S, Antipov D, et al (2012) SPAdes: A new genome assembly algorithm and its applications to single-cell sequencing. J Comput Biol 19:455-477

3. Blin K, Shaw S, Steinke K, et al (2019) antiSMASH 5.0: updates to the secondary metabolite genome mining pipeline. Nucleic Acids Res 47:W81-W87

4. Catone M V., Ruiz JA, Castellanos M, et al (2014) High polyhydroxybutyrate production in Pseudomonas extremaustralis is associated with differential expression of horizontally acquired and core genome polyhydroxyalkanoate synthase genes. PLoS One 9:e98873

5. Chaudhary DK, Kim J (2017) Ramlibacter monticola sp. nov., isolated from forest soil. Int J Syst Evol Microbiol 67:4468-4474

6. Dahal RH, Chaudhary DK, Kim J (2018) Pinisolibacter ravus gen. nov., sp. nov., isolated from pine forest soil and allocation of the genera Ancalomicrobium and Pinisolibacter to the family Ancalomicrobiaceae 
fam. nov., and emendation of the genus Ancalomicrobium Staley 1968. Int J Syst Evol Microbiol 68:1955-1962

7. Dahal RH, Kim J (2018) Fluviicola kyonggii sp. nov., a bacterium isolated from forest soil and emended description of the genus Fluviicola. Int J Syst Evol Microbiol 68:1885-1889

8. Doetsch RN (1981) Determinative Methods of Light Microscopy. In: Gerdhardt P, Murray RGE, Costilow RN, et al. (eds) Manual of Methods for General Bacteriology. American Society for Microbiology, Washington, DC, USA, pp 21-33

9. Frank JA, Reich Cl, Sharma S, et al (2008) Critical evaluation of two primers commonly used for amplification of bacterial 16S rRNA genes. Appl Environ Microbiol 74:2461-2470

10. Getachew A, Woldesenbet F (2016) Production of biodegradable plastic by polyhydroxybutyrate (PHB) accumulating bacteria using low cost agricultural waste material. BMC Res Notes 9:1-9

11. Grant JR, Stothard P (2008) The CGView Server: a comparative genomics tool for circular genomes. Nucleic Acids Res 36:W181-4

12. Heulin T, Barakat M, Christen R, et al (2003) Ramlibacter tataouinensis gen. nov., sp. nov., and Ramlibacter henchirensis sp. nov., cyst-producing bacteria isolated from subdesert soil in Tunisia. Int $\mathrm{J}$ Syst Evol Microbiol 53:589-594

13. Kim HM, Han DM, Chun BH, et al (2021) Ramlibacter algicola sp. Nov., isolated from a freshwater alga cryptomonas obovoidea. Int J Syst Evol Microbiol 71:005010

14. Komagata K, Suzuki K (1988) 4 lipid and cell-wall analysis in bacterial systematics. Methods Microbiol 19:161-207

15. Kumar S, Stecher G, Tamura K (2016) MEGA7: Molecular evolutionary genetics analysis version 7.0 for bigger datasets. Mol Biol Evol 33:1870-1874

16. Lagesen K, Hallin P, Rødland EA, et al (2007) RNAmmer: consistent and rapid annotation of ribosomal RNA genes. Nucleic Acids Res 35:3100-3108

17. Lee HJ, Lee SH, Lee SS, et al (2014) Ramlibacter solisilvae sp. nov., isolated from forest soil, and emended description of the genus Ramlibacter. Int J Syst Evol Microbiol 64:1317-1322

18. Lee I, Chalita M, Ha S-M, et al (2017) ContEst16S: an algorithm that identifies contaminated prokaryotic genomes using 16S RNA gene sequences. Int J Syst Evol Microbiol 67:2053-2057

19. Meier-Kolthoff JP, Auch AF, Klenk H-P, Göker M (2013) Genome sequence-based species delimitation with confidence intervals and improved distance functions. BMC Bioinformatics 14:60

20. Meier-Kolthoff JP, Sard JS, Carbasse S, et al (2021) TYGS and LPSN: a database tandem for fast and reliable genome-based classification and nomenclature of prokaryotes. Nucleic Acids Res

21. Minnikin DE, O'Donnell AG, Goodfellow M, et al (1984) An integrated procedure for the extraction of bacterial isoprenoid quinones and polar lipids. J Microbiol Methods 2:233-241

22. Mostafa YS, Alrumman SA, Alamri SA, et al (2020) Bioplastic (poly-3-hydroxybutyrate) production by the marine bacterium Pseudodonghicola xiamenensis through date syrup valorization and structural assessment of the biopolymer. Sci Reports 2020101 10:1-13 
23. Muneer F, Rasul I, Azeem F, et al (2020) Microbial polyhydroxyalkanoates (PHAs): Efficient replacement of synthetic polymers. J Polym Environ 28:2301-2323

24. Na SI, Kim YO, Yoon SH, et al (2018) UBCG: Up-to-date bacterial core gene set and pipeline for phylogenomic tree reconstruction. J Microbiol 56:281-285

25. Parte AC, Carbasse JS, Meier-Kolthoff JP, et al (2020) List of Prokaryotic names with Standing in Nomenclature (LPSN) moves to the DSMZ. Int J Syst Evol Microbiol 70:5607-5612

26. Props R, Monsieurs P, Vandamme P, et al (2019) Gene Expansion and Positive Selection as Bacterial Adaptations to Oligotrophic Conditions. mSphere 4:

27. Pruesse E, Peplies J, Glöckner FO (2012) SINA: Accurate high-throughput multiple sequence alignment of ribosomal RNA genes. Bioinformatics 28:1823-1829

28. Richter M, Rosselló-Móra R (2009) Shifting the genomic gold standard for the prokaryotic species definition. Proc Natl Acad Sci 106:19126-19131

29. Sasser M (1990) Bacterial identification by gas chromatographic analysis of fatty acid methyl esters (GC-FAME). MIDI Tech Note 101 Newark, MIDI Inc;1990

30. Schattner P, Brooks AN, Lowe TM (2005) The tRNAscan-SE, snoscan and snoGPS web servers for the detection of tRNAs and snoRNAs. Nucleic Acids Res 33:W686-9

31. Smibert RM, Krieg NR (1994) Phenotypic characterization. In: Gerhardt P, Murray RGE, Wood WA, Krieg NR (eds) Methods for General and Molecular Bacteriology. American Society for Microbiology, Washington DC, USA, pp 607-654

32. Tatusova T, DiCuccio M, Badretdin A, et al (2016) NCBI prokaryotic genome annotation pipeline. Nucleic Acids Res 44:6614-6624

33. Yoon S-H, Ha S-M, Lim J, et al (2017a) A large-scale evaluation of algorithms to calculate average nucleotide identity. Antonie Van Leeuwenhoek 110:1281-1286

34. Yoon SH, Ha SM, Kwon S, et al (2017b) Introducing EzBioCloud: A taxonomically united database of 16S rRNA gene sequences and whole-genome assemblies. Int J Syst Evol Microbiol 67:1613-1617

35. Zhang Z, Schwartz S, Wagner L, Miller W (2000) A greedy algorithm for aligning DNA sequences. J Comput Biol 7:203-214

\section{Figures}




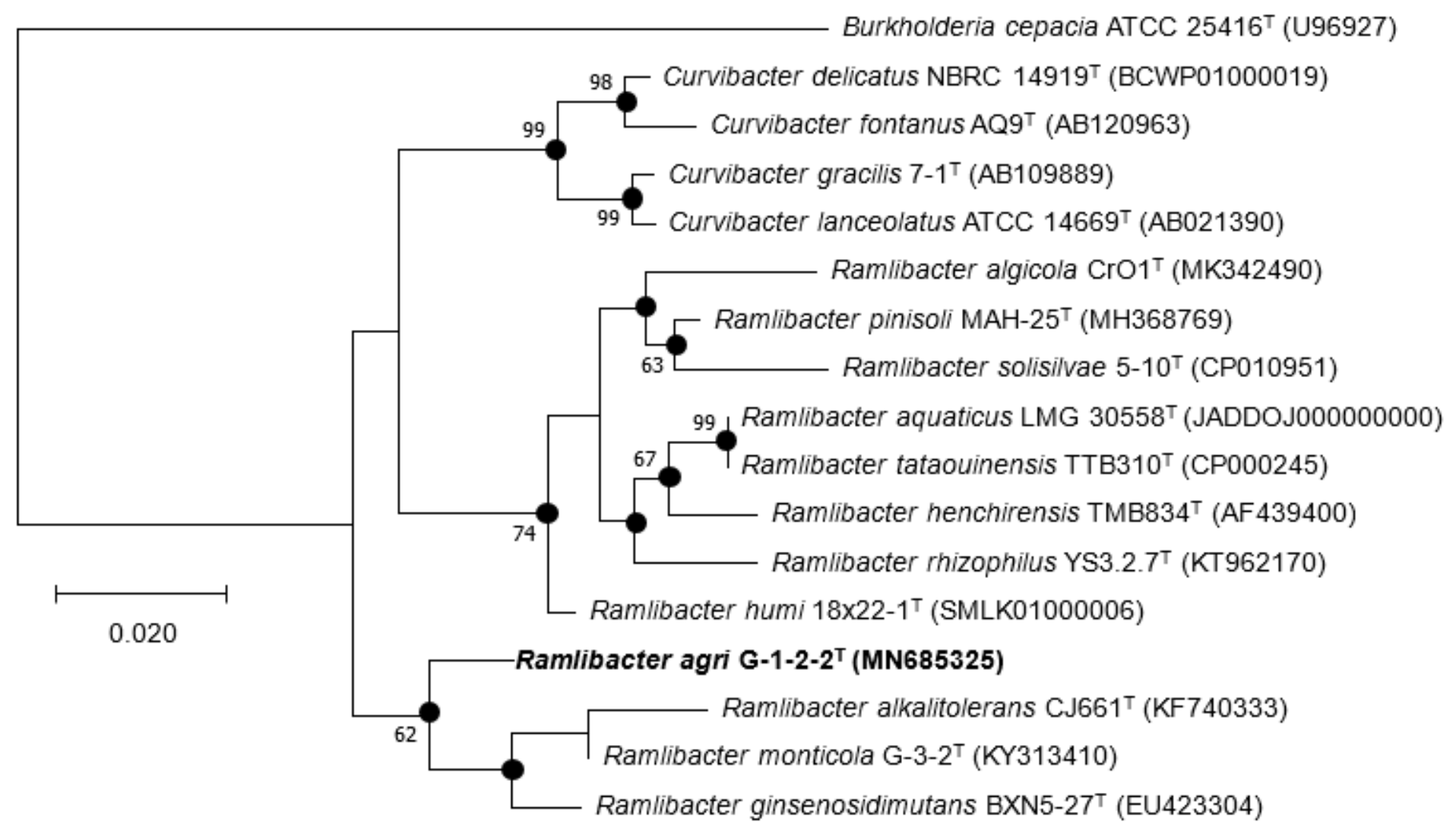

\section{Figure 1}

Maximum-likelihood (ML) phylogenetic tree based on 16S rRNA gene sequences showing the phylogenetic position of strain G-1-2-2T among the closest members of the family Comamonadaceae. Filled circles are recovered by neighbour-joining $(\mathrm{NJ})$, maximum-likelihood $(\mathrm{ML})$ and maximum-parsimony $(\mathrm{MP})$ treeing methods. Bootstrap values ( $>50 \%$ ) based on 1000 bootstrap replicates are shown at branch nodes. Burkholderia cepacia ATCC 25416T was used as an out-group. Numbers in parentheses indicate GenBank accession numbers. Bar, 0.020 substitutions per nucleotide position. 


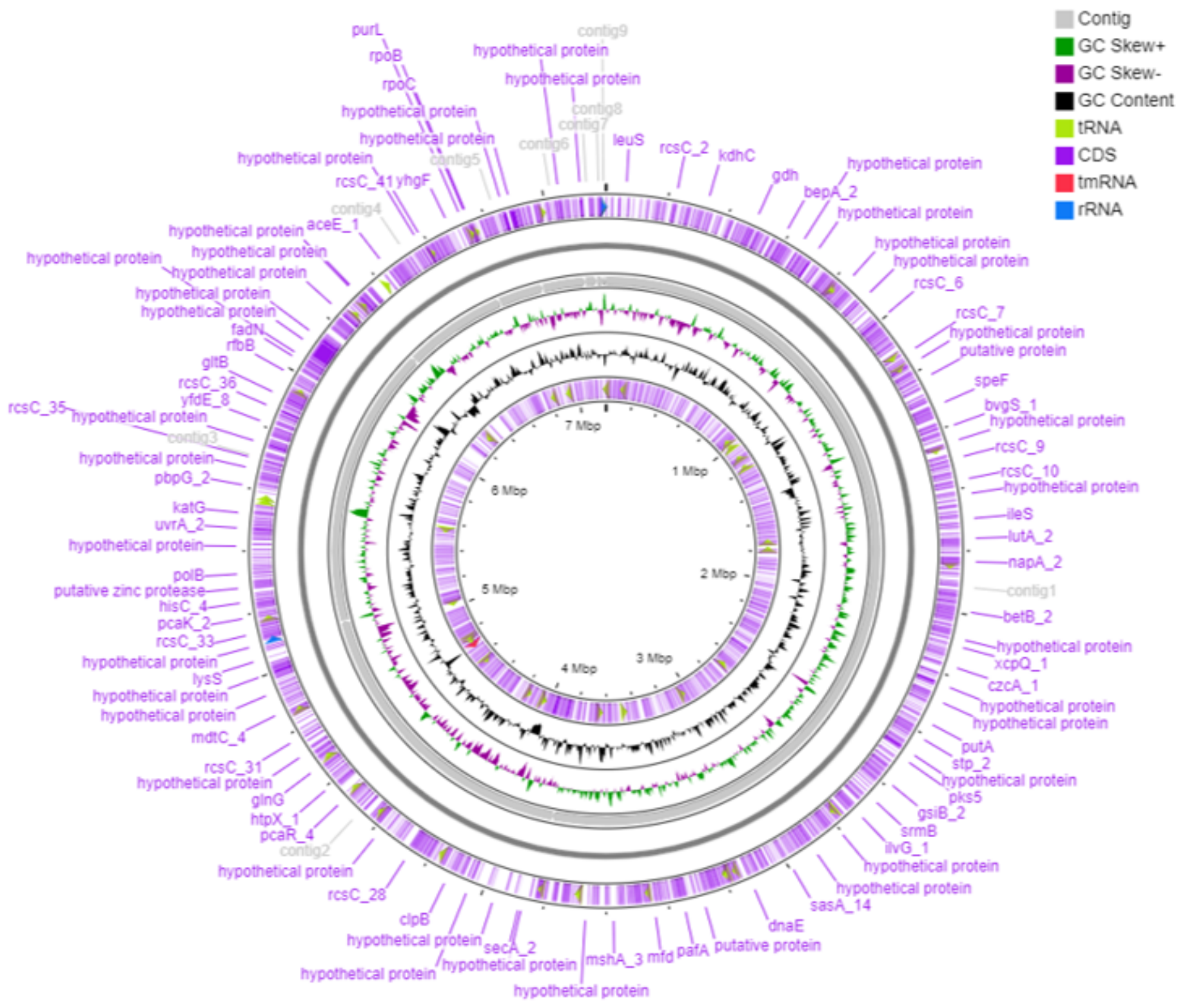

Figure 2

Graphical genomic map of strain G-1-2-2T. From outside to the center: Genes on forward strand, genes on reverse strand, RNA genes (tRNAs purple blue, rRNAs blue, tmRNA red), GC content, and GC skew.

\section{Supplementary Files}

This is a list of supplementary files associated with this preprint. Click to download.

- SupplementaryRamlibacteragriAVL.docx 